\title{
Teaching Practice and Research on Cultivating Excellent Avionics Engineer in Digital Signal Processing Course
}

\author{
Zhibo SHI \\ Aeronautical Automation College, Civil Aviation University of China, Tianjin 300300, P.R.China \\ Jie BAI, Dan SUN \\ Tianjin Key Laboratory for Airworthiness and Maintenance of Civil Aircraft, Civil Aviation University of \\ China, Tianjin, 300300, P.R.China
}

\begin{abstract}
With the implementation of the plan for educating and training outstanding engineers, as well as the promotion of the CDIO Teaching mode, the education should continue to explore new laws and models in the training of innovative talent in the engineering field. Firstly, the course introduction is considered as the guide into the DSP in order to enhance students' sense of professional identity and belonging. Then, the practice and design should be organized elaborately under the CDIO model for the purpose of stimulating students' desire to learn the course and to solve problems in engineering practice. Matlab and other specific applications as a development tool are used to realize the specific applications. Finally, the paper tried to establish a new training model by the reasonable combination of the 'excellent program' and the CDIO teaching model according to the problems from the teach process.
\end{abstract}

KEYWORD: digital signal processing; education and training programs of excellent engineer; CDIO; specialty construction; Matlab.

\section{INTRODUCTION}

The Ministry of Education launched the "plan for educating and training outstanding engineers" (PETOE) [1-2] in June 2010, which aimed at "cultivating a large number of high quality engineering and technical personnel who have innovative ability and adapt to the needs of economic and social development."[3-4] With the rapid development of China's civil aviation industry, and steadily promote the development of large aircraft which made in China. The support and expectation to Civil Aviation was given in the Nation "Twelfth Five Year" plan. The higher requirements are put forward to the civil aviation engineering talents when the CAAC is moving towards the commercial aviation powerful nation gradually from the commercial aviation great nation. How to effectively cultivate a large number of innovative engineers who suitable need for civil aviation industry, having the high quality, high technical level and high practical ability, which is the responsibility and obligation to the incumbent civil aviation college. Therefore, the traditional mode of training engineering talents should be reformed and innovated, which requires integrating the curriculum content and designing the new teaching process. An effective model of cultivating talents should be explored combined with the "CDIO" educational philosophy[5-6].

Information science and technology has great development and application in the industrial, life, commercial and aerospace fields etc. Digital equipments are used to replace the analog equipments more and more in the modern aircraft, especially in the Airbus A380 and Boeing B-787 aircraft. "Digital signal processing" course is an important professional basic course to specialty of electronic and information engineering and specialty of communication. It is also one of required professional basic courses for the aviation electronic specialty in our college. How to combine "CDIO" teaching concept in the course, which is one of the important problems in the reform and practice of exploration, because its curriculum theory is strong and the characteristics of mathematical formulas and mathematical concepts more in which.

This article introduced some measures in the teaching process, from the professional curriculum system of Avionics, which is to attract students in the beginning, to seize student in the explaining, to encourage students in the realized design. Visual teaching and practice on the course are used by MATLAB simulation software and video technology. The students' hands-on design and realization of the experimental process in the course 
are encouraged, so as to improve the students' understanding of the course and ability of application analysis.

\section{APPLICATION AS THE BASIS TO ENHANCE THE PROFESSIONAL IDENTITY AND BELONGING}

From business to military science, geological exploration to the aerospace industry, the medical treatment technology to the cause of science exploration, can be seen everywhere the digital signal processing technology figure. Digital signal processing system is a magnificent building. Good introduction to explain is to help the students can get a glimpse of the majestic building in periphery, which can strengthen the students to grasp the trend of the digital signal processing technology and stimulate their yearning to entered the building.

In the teaching, professional construction and characteristics of civil aviation were combined under the CDIO teaching mode based on the introduction, which has strong presentation on the application of digital signal processing technology in the aircraft design and maintenance. As the plane voice recorder analysis technology, data communication of aircraft radio system, spectrum analyzer for the aero-engine maintenance etc, which greatly increased the learning enthusiasm of students. And some problems were answered. Why study this course? What is the action of the course? How it can work in your future job? These would enhance the professional identity and belonging sense when they are answered.

\section{THEORY TO EXPLAIN INTERLOCKING AND DESIGN TEST REFLECTED EVERYWHERE}

Digital signal processing has strong theory and practical application. In the arrangement of aviation electronic professional curriculum system, the analysis of linear systems and digital signal processing are given lessons at the same time. Therefore, it puts forward higher request to the student, and also posed a challenge to the teachers in the teaching process, which needs to optimize the knowledge system and content. When the knowledge structure was optimized, the ability of analyzing problems and solving problems should be improved and paid more attention.

Teaching system begins from signal and ends to system. The digital signal and digital system are separated but without be isolated. The four major transforms, which are the Laplace transform, the continued Fourier transform, $\mathrm{Z}$ transform and the discrete Fourier transform, should be highlighted in the course, particularly their mathematical concepts, physics and engineering significance. In the teaching process, theory deduction in mathematics should be diluted, and the time domain and frequency domain are combined with analysis of the relevant system in the design process.

CDIO represents conception, design, implementation and operation, which is a kind of advanced education, is established by MIT and other three universities through practice and research[7-8]. The mode focuses on training students' engineering capability and the consistency of the knowledge as well as the complementarities and continuity. CDIO teaching mode, which accords with the engineering personnel training rules, represents the advanced education method[9-10]. The mode satisfies the requirement of cultivating excellent avionics engineer, which can be enforceable to enhance the internship and practical training, such as digital system design of aircraft instruments landing system (ILS), spectrum analysis of cockpit audio receiver, spectrum analysis of aero engine vibration signal and airborne radar signal analysis etc. The learning process of students and professional characteristics were combined, which let the students finish the practice of maintenance technique in theory learning and realize the theory combination with application course in practice.

In addition, the teaching method should be improved which is the start in the practice of CDIO and Excellence Program. The theoretical derivation and exercise under the traditional method would move to the heuristic teaching. According to the experience of three years, the ability of solving problem to the students had significantly enhanced and performance also had a significant increase.

\section{MAKE FULL USE OF VARIOUS TOOLS TO EXPLAIN THE APPLICATION SUCH AS MATLAB ETC}

When the curriculum had been meticulously organized and the knowledge had been carefully concise, the tools such as Matlab should be good at using in the class, which can combine teaching with demonstration to meet the students' understanding of the learning requirements in many aspects. Matlab is a set of high performance software for visualization in scientific and engineering technology, which is developed by Mathworks Company. It has powerful computing ability and visual interface and more simple to meet the people's way of thinking compared to the $\mathrm{C}$ language and Fortran in the operational implementation. It is very convenient in signal analysis, processing and design even though to the people who had weak ability of programming. 
It has become the main tool for digital signal processing applications and simulation analysis.

In the actual teaching, visual explanation of some difficulty and key can be given by Matlab. The abstract and concrete problems can be the visual which is beneficial to obtain good teaching effect, such as the physical meaning of DFT and its application in spectral analysis of signals, circular convolution etc. If they are relied on manual drawing to explain, this is not only time-consuming but also not easy to understand. The use of Matlab will boost your efforts, which can be shown in Fig 1.
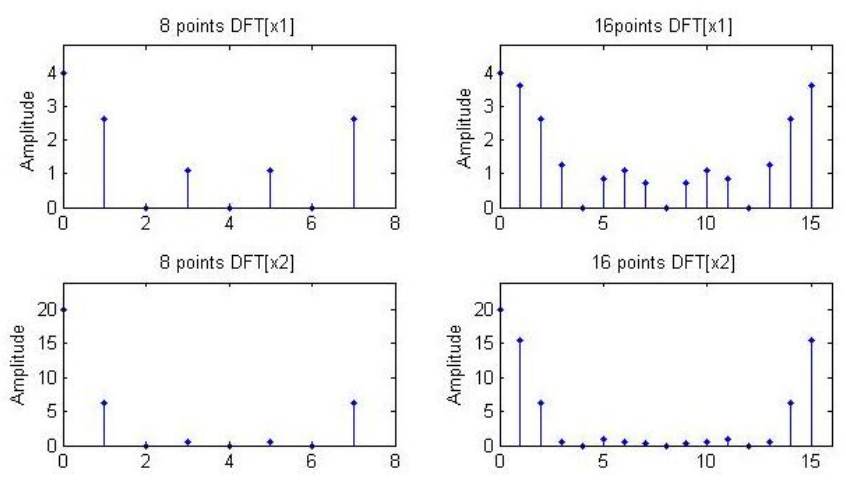

8 points DFT $[\times 3]$
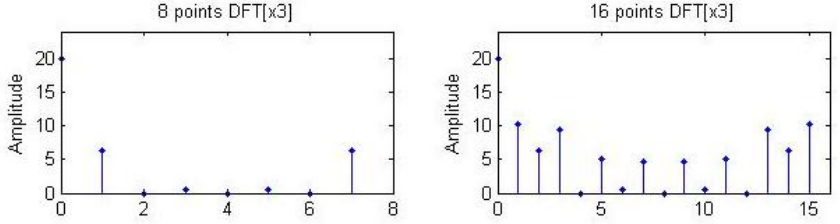

Figure 1. DFT simulated in the Matlab

In solving practical engineering problems, the Matlab software is also a capable assistant, which can be illustrated by denoising for the cockpit voice recorder (CVR) based on filter as an example. Voice information of aircraft CVR contains the sound of words, all kinds of noise and background noise etc. In which, the background sound is very important to the investigation on the flight accident. But it is relatively difficult to extract. So accurate analysis on the parameters of the background sound and then take it from a mixture of cockpit information extracted becomes important in flight accident investigation. Through the comparison of different spectral characteristics accurately of the background sound, that can determine what frequency exists accurately, which is one of the important basis for investigating. To some degree, harmonic noise filter can reduce these noises. Design of the filter can be shown in Fig 2.

By the design of experimental, the design principle and application of filter can be taught clearly. And which will give guidance and analysis on the design of hardware for the system implementation. A rich and colorful world of the DSP will be exhibited by utilizing matlab.
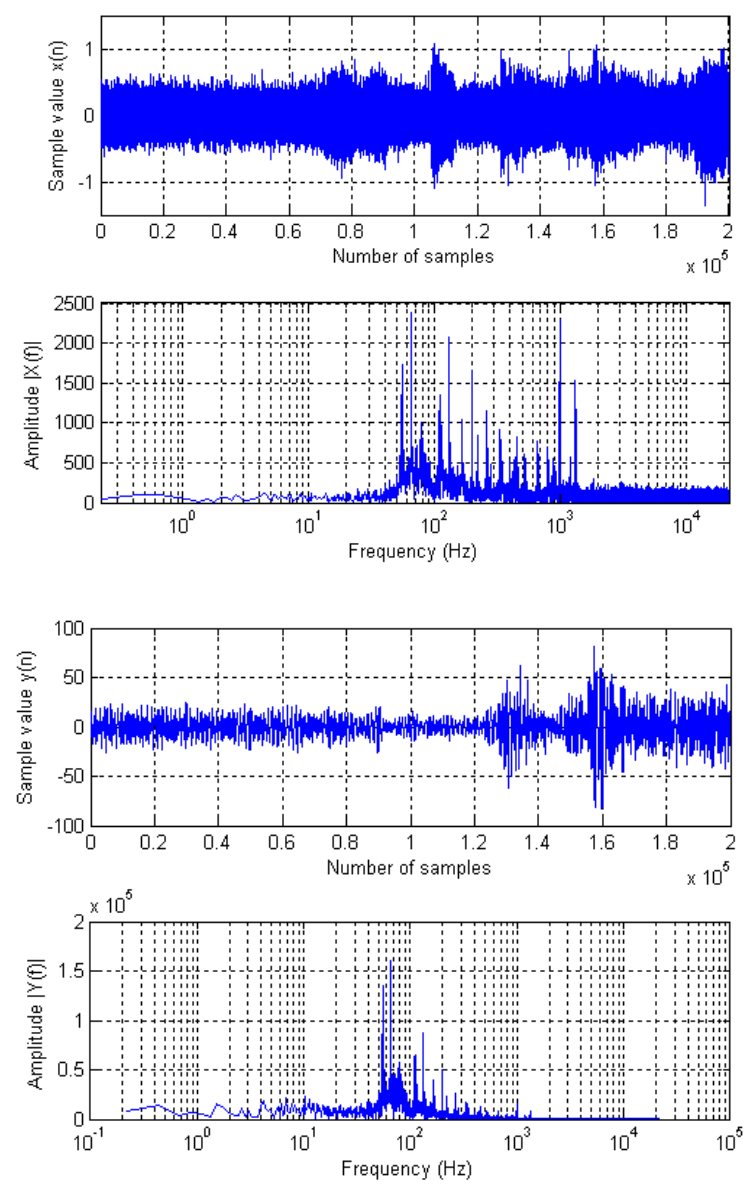

Figure 2. application of the filter in the CVR to reduce the noise

\section{REFLECTIONS ON THE CARRYING OUT OF THE PETOE IN DSP COURSE}

PETOE is a major reform project of our country in the field of education, which is the strategy of reinvigorating China through human resource development and power engineering education. The national universities have regarded it as an important opportunity to promote development and major of engineering education reform. The university that seizes the opportunity will strive for further improvement in teaching level.

The full mobilization has been implemented in the mind in CAUC, and the safeguards have been given in the policy. But how to break the traditional mode of education and to improve the teaching method, which depends on practice to explore the teaching mode that suitable for the college. The method using in DSP course will serve a good attempt.

External causes that playing a role need through the internal cause. The student is the main body of engineering education, whose participation will be an important prerequisite for success in the PETOE. Learn from actions, and act from learning. In the avionics of professional teaching, many cleverly engineered projects had been applied in the learning process by appeals of the aerospace science. The 
initial implementation has obtained the certain effect. If specific implementation with software and hardware put into practice in the open laboratory or work combined with outside enterprises, which will obtain better training effect further.

\section{SUMMARY}

The CDIO teaching mode and PETOE were combined in the DSP course. The lecture was wellprepared and cleverly engineered projects were welldesigned, which stimulates students' interest in learning and improves students' ability. If it is explored the education mode actively, will achieve significant results in higher engineering education. It explores a new mode of cultivating innovation application talents, through its implementation of the plan and CDIO.

\section{REFERENCES}

[1] Wang Shuguo. Thinking about the training mode of topnotch talent in first-class university. China Higher Education. 2011.02:9-11.

[2] Lin Jian. The quality requirements of "A plan for education and training outstanding engineers" and engineering education accreditation. Research in Higher Education of Engineering. 2013.07:49-61

[3] Zhang Xiaobao. Reflections on the "985 Project" universities' plan for education and producing excellent engineers: from the perspective of curriculum. Journal of Higher Education Management.2013.Vol(7):24-30.

[4] Zhang Hanqiang, Guo Baolong, etc. Inspirations of overseas cooperative education of production and learning for Chinese implementation of the plan of cultivating excellent engineers. Higher Education of Sciences. 2011. Vol(4):49-53

[5] Takemata, Kazuya, etc. Engineering project-based learning under the CDIO concept. Proceedings of 2013 IEEE International Conference on Teaching, Assessment and Learning for Engineering, TALE 2013, p 258-261.

[6] Tenhunen, Lauri Juhani, etc. Rapid prototyping service model by the CDIO educational framework. Annals of DAAAM and Proceedings of the International DAAAM Symposium, p 1571-1572, 2010.

[7] Li Wenjing, Zhang Chunming, etc. Reformation and exploration of higher engineering education based on CDIO syllabus. Lecture Notes in Electrical Engineering, v 112 LNEE, p 587-591, 2011.

[8] Yin Niansheng, Yu, Hanqi, etc. Reform and practice of schools and enterprises build CDIO engineering education mode. Engineering Education and Management. Vol 2, p 45-48, 2011.

[9] Marasco Emily, Behjat Laleh. Integrating creativity into elementary electrical engineering education using CDIO and project-based learning. 2013 IEEE International Conference on Microelectronic Systems Education, MSE 2013, p 44-47, 2013.

[10] Svensson Tomas, Gunnarsson Svante. A Design-BuildTest course in electronics based on the CDIO framework for engineering education. International Journal of Electrical Engineering Education, October 2012 v 49, n 4, p 349-364. 